\title{
"It All Goes Back to the Services": A Rural/Urban Comparison of Service Providers' Perceptions of Challenges and Facilitators to Disability Services
}

\author{
Moya L. Alfonso' ${ }^{1}$, Ashley Walker ${ }^{1}$, Akrati Gupta1 ${ }^{1}$, Joseph Telfair ${ }^{1}$, Gavin Colquit ${ }^{2}$ \\ ${ }^{1}$ Department of Community Health, Georgia Southern University, Statesboro, GA, USA \\ ${ }^{2}$ Department of Health and Kinesiology, Georgia Southern University, Statesboro, GA, USA \\ Email: malfonso@georgiasouthern.edu, awalker@georgiasouthern.edu, akrati gupta@georgiasouthern.edu, \\ jtelfair@georgiasouthern.edu,gcolquitt@georgiasouthern.edu
}

Received 20 June 2015; accepted 25 October 2015; published 29 October 2015

Copyright (C) 2015 by authors and Scientific Research Publishing Inc.

This work is licensed under the Creative Commons Attribution International License (CC BY).

http://creativecommons.org/licenses/by/4.0/

(c) (i) Open Access

\begin{abstract}
Purpose: The purpose of this qualitative study was to explore rural/urban differences in service providers' perceptions of challenges and facilitators to services for children with special health care needs (CSHN) and their families in southeast Georgia. Methodology: A total of 23 individual interviews were conducted with service providers in one rural county in southeast Georgia $(N=12)$ and in one urban county in north central Georgia $(N=11)$. Interviews were based on the National Survey of Children with Special Health Care Needs 2009-2010 survey. All interviews were audio recorded, transcribed and coded with the intent of identifying themes and illustrative quotes. Findings: Service providers discussed a variety of challenges to accessing services related to socioeconomic status and the transition out of the school system. Urban and rural service providers' perceptions were similar overall, with the exception of lack of transportation and access to a variety of services in rural area. Service providers overcome challenges through identifying parents' needs and limitations and adapting service provision. Some of the facilitators mentioned by both urban and rural service providers are availability of transportation and resources. Practical Implications: The results of this study provide public health practice and policy implications that could guide the pathways of targeted interventions to improve the access and availability of variety of services for CSHCN. Originality/value of paper: This paper represents an in-depth exploration of service provider's perceptions of challenges and facilitators related to service provision for children with special healthcare needs.
\end{abstract}

\section{Keywords}

Disability, Adolescents, Qualitative, Access, Service, Service Providers 


\section{Introduction}

According to American Community Survey, disability is characterized by serious difficulty with four basic areas of functioning-hearing, vision, cognition, and ambulation [1]. In 2013, individuals with disabilities comprised $12.6 \%$ of the total population in the United States and of these $12.6 \%$, approximately, $9 \%$ reported having physical disability and about $3 \%$ reported having some form of intellectual disability [1]. According to US Census Bureau, 5.9\% of young individuals ages 16 to 34 are affected by some type of disability [1]. A study estimated that in 2011, approximately 2.3 million adolescents of ages 12 to 17 years was affected by one or more types of disability and the overall rate of disability for children $<18$ years old increased to $15.6 \%$ between 2001 and 2011 [2].

Since youth make up considerable portion of individuals with disabilities; several studies have explored differences in utilization, accessibility and availability of support services for children with special health care needs (CSHCN) while transitioning to adult services, from parents', teachers' and youth perspectives [2]-[5]. However, there is lack in our understanding of the challenges to accessibility, availability and utilization of support services for transitioning CSHCN from service providers' perspective. Therefore, it is important to explore and identify the providers' perceptions of challenges and facilitators that they encounter on daily basis while providing services for CSHCN and their families. Moreover, it is also important to know the challenges encountered by service providers because studies have shown that an effective collaboration between service providers, caregivers and adolescents with disabilities produce positive developmental outcomes [3] [6]. Thus, the focus of this study is to identify, explore, and compare barriers and facilitators for engaging in support services for youth from service provider's perspectives in urban and rural Georgia.

Georgia is comparable to national averages when it comes to disability statistics. In Georgia, approximately $12 \%$ of the population has one or more types of disability, and, of these, about $4 \%$ have cognitive impairment, and approximately $2 \%$ have hearing, visual or ambulatory impairment [1]. Out of $12 \%$ of this population, nearly $6 \%$ are youth between ages 16 to 20 years [1]. Over 500,000 CSHCN are currently transitioning into adult services in the United States in hopes of independent living [2] [7]. CSHCN often face challenges in transitioning to adult services such as vocation, education and quality health care [8]-[10]. Studies have identified several environmental, structural, financial and social challenges that act as barriers for engaging in these services [7]. It is also noteworthy that the magnitude and presentation of these barriers can differ by the geographic location-urban versus rural [5] [11]-[13].

In Georgia, nearly $15 \%$ of individuals with disabilities live in rural areas, while $11 \%$ live in urban areas [1]. The differences between the accessibility and availability of services in rural and urban areas can potentially impact the perceptions about the quality and quantity of services available to individuals with disabilities [14]. The majority of the services for youth with disabilities are provided within educational institutions, thus, after graduation there is large drop in the amount of services that are available and accessible to this population and the drop in services varies depending upon their geographic location [15]-[17]. Since Georgia is comparable to national averages in disability statistics, it would be beneficial to identify rural/urban differences in challenges and facilitators to services for CSHCN and their families. The purpose of this qualitative study was to explore rural/urban differences in service providers' perceptions of challenges and facilitators to services for CSHCN and their families in southeast Georgia. The results of this study provide public health practice and policy implications that could guide the pathways of targeted interventions to improve the access and availability of variety of services for CSHCN.

\section{Methodology}

\subsection{Setting}

Study counties were selected based on the urbanization categories of the National Center for Health Statistics (NCHS) 2006 NCHS Urban-Rural Classification Scheme for Counties [18]. The urban county was classified as "large metro" and the rural county was classified as "micropolitan". Recent surveillance data indicated that 7.9\% of individuals between the ages of 5 and 17 and $8.4 \%$ of individuals between the ages of 18 and 34 years in the rural county reported a disability [1]. Approximately 3.5\% of the population between the ages 5 and 17 and $4.7 \%$ of the population between the ages of 18 and 34 in the urban county reported a disability [1]. 


\subsection{Participants}

A total of 23 individual interviews were conducted with service providers in one rural county in southeast Georgia $(N=12)$ and in one urban county in north central Georgia $(N=11)$. Participants were recruited if they were a direct provider of a support (e.g. respite care or social services) or health service. To recruit participants, the researchers contacted two agencies (one from each area) that function to link families and individuals living with a disability to service providers in the surrounding area. Participants included health practitioners (physical therapist, occupational therapist, nurses), service agency staff and administration (advocacy groups, resource centers, recreation personnel), and school support personnel (adapted physical education specialist, physical, and speech therapists).

\subsection{Procedures}

Each interview was conducted by a trained interviewer who used an interview guide based on the National Survey of Children with Special Health Care Needs 2009-2010 survey [19]. The guide covered questions specific to perceived challenges and facilitators to obtaining health and support services for children and families living with the disability. Each interview lasted approximately 60 minutes. The study was approved by the [masked for review] institutional review board.

\subsection{Data Analysis}

All interviews were audio recorded and transcribed verbatim. To carry out the analysis, transcripts were imported into MAXQDA V 11 software program. Each transcript was coded by a primary coder and was then shared with a secondary coder for review. To ensure consistency and achieve reliability, both coders communicated to discuss differences in coding to reach $100 \%$ consensus. Illustrative quotes were selected from both counties with the intent of demonstrating differences in challenges and facilitators.

\section{Results}

The following sections summarize major themes. Whereas themes cut across areas, differences between urban and rural areas are noted within each theme.

\subsection{Barriers from the Perspective of Rural and Urban Service Providers}

\subsubsection{Socioeconomic Status and Health Insurance- "Determining Factors"}

Socio-economic status is the determining factor in overcoming challenges to accessing services for children with disabilities. From the initial diagnosis to geriatric parents caring for an adult child with disabilities, raising a child with a disability can be an overwhelming process, particularly for low-income parents. Parents who are not limited by finances can afford transportation to and from services within and outside of their home county, can afford after school and summer respite care, live in homes and own vehicles that can accommodate specialized equipment, and can arrange for their child to participate in community-based activities including organized sports for youth with disabilities. On the other hand, low income parents usually lack health insurance and cannot afford the out of pocket cost of services for child with disabilities which acts as one of the major challenges in accessing supportive services for youth with disabilities. As one rural service provider highlighted-

"I think that the frequency of use may be related to social economic standing in the community. If the individual family has transportation and they have money and they're educated they're more likely to come in contact with service provision; on the other hand, those families who are not well educated, socioeconomically deprived, they're less likely to come into contact with services.”-Rural Service Provider

Urban service providers also mentioned that their clients often complain about difficulty in accessing services because they don't have Medicaid or other private health insurance to cover the cost of the services. Most of the services available in the urban counties are paid services, and individuals who do not have Medicaid or other private health insurance either have to pay out of pocket for the services or have to find organizations that provide free services. Such as an urban service provider stated, "I think probably a lot in that I know people that will only access whatever support their health insurance offers. So, if it's not available in insurance, then 
they're not going to do it." Providers also pointed out that even if one has Medicaid or Medicare, it is not guaranteed that it will cover full cost of the services. Moreover, lack of Medicaid or other private health insurance also hinders access to preventative care such as immunizations, which in longer run can lead to greater health risks. In addition to this, according to service providers, low income parents face additional challenges including grandparents raising grandchildren, illiteracy, unsafe neighborhoods, inability to stay home with their child, and lack of education. Perhaps, most importantly, low income parents face blame. They are said to have low motivation, lack of follow through, lack of time, denial, and a general "belief that it's someone else's job to take care of their child."

Lack of transportation, public or private, also act a challenge in accessing support services. Both urban and rural service providers mentioned that even though public transportation is available in urban areas, some clients find it difficult to pay for public transportation because of the limited income or because parents themselves are working and have time restrictions, so they usually have to seek help from others to take their child to supportive services. As one rural service provider illustrated-

"Transportation is an issue for some families. We try to work with families. There are some families driving in from Glenville or Reidsville and we know that they could come or their child could benefit from coming twice a week but their families just can afford to drive back and forth so we work we always work very closely with the parents, sometimes they're in the sessions with us and we're showing them this is what you do this week. So we teach the parents to become their child's therapist so we can help them not have to so the transportation so we see them once a week and teach them things to do on the week they're not coming."

\section{- Rural Service Provider}

In reality, low income parents, more so than middle to upper class parents, may not understand their child's diagnosis, might face multiple challenges to accessing services, and might not feel sufficiently empowered to advocate for services. In terms of the school system, parents face additional challenges to obtaining services for their child, including not being listened to and having to work as parents who might not understand their child's unique needs. As well as low income parents' tendency to have negative experiences with school systems might also act as a barrier that can be especially overwhelming and might prevent them from working with schools to address their child's needs. As one rural service provider highlighted-

"You have to understand the system, you're going to be there for so many years and you have to work through it. So, that's my joy to explain to parents. And getting the school system to open up and listen to parents because they don't sometimes. They are the experts and we respect that but sometimes you have to listen to parents."-Rural Service Provider

\subsubsection{Transition from School-"Nothing To Do"}

Whereas the transition into the school system is perceived as an easier process for youth with disabilities, the transition out of the school system is fraught with difficulties. In most of the cases, from the age of 3 to 22 years, families of youth with disabilities have the support of school system in caring for their child and accessing key services. Upon the child's $22^{\text {nd }}$ birthday, children with disabilities can no longer attend school. The framework for transition focuses on post-secondary opportunities, employment options, living opportunities, and recreation and leisure (Georgia Department of Education 2011). Although transition plans are required in the state of Georgia starting in ninth grade or the age of 16 , transitioning into a community with a lack of specialized services for youth with disabilities is a stressful time. The emotional stress is usually followed by lack of proper transition plan by parents and transition teachers at schools. As illustrated by a rural service provider-

"They go from this nurturing environment, for a lot of these kids there's somebody there taking care of them and a lot of these kids started the preschool disability program when they were three years old. You figure from 3 years to 22 years you've had someone basically looking out for you and boy the day you turn 22 your done, and if there aren't any services out there for say to get a job or respite care, it would just be a shock. I can't imagine since you were 3 years old and all of the sudden you're 22 and your world take a 180. Not only for kids but for parents too as we mentioned before. They've had however many years of somebody taking care or looking out or educating their child to running into a stone wall...and nothing being available."-Rural Service Provider 
According to service providers, upon graduation from high school usually youth with disabilities "sit at home and do nothing" or return to school for further studies. In many cases, this situation has a dramatic impact on families, with one consequence being the loss of parental employment. Overall, results suggested the main barrier to a smooth transition out of school, is a cycle of dependence that is created by government and school interaction. Many families come to rely on financial and support services provided by the government and school system. Transition threatens this dependence and requires parents to function independently to receive services for their child. In many cases, for example, parents are afraid to engage their child in supportive employment after school for fear of loss of social security and disability checks. Without accurate information on when to plan for transition, what their children are capable of after graduating and how to access and maintain available services including government funding, the transition out of high school will continue to result in many young adults with disabilities being unable to become functional, contributing members of their communities.

"It's very, very limited. If they're lucky enough, I had a parent in here yesterday whose son graduated from high school and for the summer he was lucky enough to get accepted into a camp for individuals with disabilities. The camp is paid for by federal monies, she was able to get some sort of grant because she's jobless and there is no father. So the boy is able to go and spend several weeks at camp but in two weeks he's coming home to nothing and literally mom is in tears cause she just got a job and the boy's coming home and her fear is she's going to have to quit her job to stay at home with her son, so now her little step that she's made progress with is going to be taken away."-Rural Service Provider

Furthermore, according to service providers, parents are often unprepared to handle the reduction in services previously assisted by the school system once the youth graduates from high school. For example, speech therapy and physical activity opportunities decrease once the youth graduates high school. The loss of services upon graduation leads to eventual declines in youth functioning and quality of life. Over and over, service providers discussed the lack of planning for transitional issues on the part of parents and, in some cases, schools. Parents were described as waiting to the last minute to apply for transitional services, often because they were unaware of the time requirements for waiting lists and eventual receipt to any of the services. Schools, on the other hand, were described as beginning the transition discussion with parents too late in the process.

Both rural and urban service providers suggested overcoming challenges related to transition by encouraging discussions among schools, service providers, and families of disabled children as early as $6^{\text {th }}$ grade. However, the state of Georgia only requires transition to begin at the beginning of high school or the age of 16 years [20]. Starting the conversation early would enable parents to understand the process and plan before the arrival of the transition stage. Additionally, it was suggested by both urban and rural providers that transition teachers should also assist youth with disabilities in developing both soft and functional skills. The youth with disabilities usually fail to keep their jobs because limited use of soft skills such as workplace etiquette, etc. Furthermore, even if the youth is capable to sustain a job, some parents prevent or discourage them from getting employment because either they are afraid of their independence or are worried to lose social security and Medicaid money if their child starts earning a paycheck.

\subsection{Facilitators from the Perspective of Rural and Urban Service Providers}

\section{Overcoming Challenges- "There Is Hope"}

Whereas parents of children with disabilities face numerous challenges in accessing services for their children, there are several factors that facilitate access to services. Both rural and urban providers can and do attempt to help overcome challenges through identifying parents' needs and limitations and adapting service provisions to meet their needs. Some of the facilitators mentioned by both urban and rural service providers are-availability of transportation and resources (financial and institutional). To overcome transportation challenges, rural service providers mentioned that they include parents in service provisions and train them to deliver services on their own in lieu of more frequently accessing services. Whereas in urban areas, the availability of public transportation makes it more feasible to access support services for youth with disabilities and their parents.

Apart from the aforementioned services, some urban service providers offer family therapy services such as training and coaching for the parents. The training and coaching focuses on developing skill sets among parents which helps them in identifying and fulfilling the specific needs of their child and also deals with connecting parents to resources that they need such as vocation services, transition services, life and social skills sessions, 
community training, cognitive therapy, physical therapy, speech and language therapy, and occupational therapy.

\section{Discussion}

Consistent with existing literature [11] [12], our providers identified financial resources and insurance coverage as significant barriers to access support services needed for families that will allow them to achieve good health related. However, there were key differences between structural and actual access to needed services. Providers indicated that their clients had limited access to structural services including Medicaid and other forms of insurance coverage, due to financial, social (family) and system related challenges. This paradigm of access and availability has been seen in other studies examining the role of structural context (resources and settings) and service provisions [14], although the barrier of transportation has been more frequently observed in rural contexts [5] [11] [12].

Findings from the present study supported the work of others that there is a critical interplay between roles of the family and social environments in which one lives [7]. For low SES parents in this study, understanding of the diagnosis of the child and their ability to provide home care influenced their ability to obtain, receive and utilize available benefits. Providers indicated that these caregivers were less likely to seek out necessary school-based information due to their own negative experiences in school. These findings suggest that efforts to make organizational level changes designed to reduce negative perceptions and the disconnection of clients and families should be made. There is a need to recognize and address inherent social inequities that may compound the inherent difficulties of assuring care for youth with special health needs.

These inequities are particularly acute when considering transition services out of the school for youth with special need. Providers in this study echoed findings from many previous studies that the process of finding employment, pursing additional educational or vocation training, and being included into the community [2] [21] is difficult because there is limited supports outside of pediatric settings. Service providers indicated that the transition process leaves most families in a position of having "nothing to do" because they were caught in a cycle of dependence on pediatric and related institutions to meet the needs of the child. Some providers indicated difficulties in implementing supportive employment programs due to a loss of benefits paid directly to the primary caregiver and the means to understand and use such services. These results highlight the need for parent education and training, as well as structural changes needed to keep in place targeted financial supports for the youth. Although policy has been shown to contribute lack of post-secondary opportunities for individuals with disabilities [21]-[24], these results suggest that both financial resources and education are significant barriers to a successful transition.

Despite the many difficulties that families of children with disabilities face, service providers and families reported key strategies to meet the needs of their child. Rural providers used educational strategies to teach parents how to better care for their child and be less dependent on transportation to access the service. Urban service providers reported using additional educational techniques such as parent-to-parent training and coaching. The importance of collaboration between the family and provider has also been highlighted in the literature [3] [6].

Delivery of services with youth with disabilities has been and remains a challenge. Studies that focus on the perspective of those providing services, particularly those with a "solution-orientation" are rare. The study discussed herein sought to shed light on not only the challenges faced, but also the solution-based approaches to the provision of services for youth with disabilities in rural southeast Georgia, USA.

\section{Funding}

This study was supported in part by funds from the Office of the Vice President for Research and Economic Development and the Jack N. Averitt College of Graduate Studies at Georgia Southern University.

\section{References}

[1] United States Census Bureau (2013) American Community Survey. http://factfinder2.census.gov/faces/tableservices/jsf/pages/productview.xhtml?fpt=table

[2] Geenen, S.J., Powers, L.E. and Sells, W. (2003) Understanding the Role of Health Care Providers during the Transition of Adolescents with Disabilities and Special Health care Needs. Journal of Adolescent Health, 32, 225-233. http://dx.doi.org/10.1016/S1054-139X(02)00396-8

[3] Knapp, C.A., Madden, V.L. and Marcu, M.I. (2010) Factors That Affect Parent Perceptions of Provider-Family Part- 
nership for Children with Special Healthcare Needs. Maternal and Child Health Journal, 14, 742-750. http://dx.doi.org/10.1007/s10995-009-0503-0

[4] Reiss, J.G., Gibson, R.W. and Walker, L.R. (2005) Healthcare Transition: Youth, Family, and Provider Perspectives. Pediatrics, 115, 112-120.

[5] Sheehey, P.H. and Black, R.S. (2003) Transition Outcomes of Young Adults with Disabilities in Rural Areas: A Research Synthesis. Rural Special Education Quarterly, 22, 3-15.

[6] Ungar, M., Liebenberg, L., Landry, N. and Ikeda, J. (2012) Caregivers, Young People with Complex Needs, and Multiple Service Providers: A Study of Triangulated Relationships. Family Process, 51, 193-206. http://dx.doi.org/10.1111/j.1545-5300.2012.01395.x

[7] Stewart, D., Gorter, J.W. and Freeman, M. (2013) Transitions to Adulthood for Youth with Disabilities: Emerging Themes for Practice and Research. The Prevention Researcher, 20, 3-6.

[8] Brewer, D., Karpur, A., Pi, S., Erickson, W., Unger, D. and Malzer, V. (2011) Evaluation of Multi-Site Transition to Adulthood Program for Youth with Disabilities. Journal of Rehabilitation, 7, 3-13.

[9] Camacho, C.B. and Hemmeter, J. (2013) Linking Youth Transition Support Services: Results from Two Demonstration Projects. Social Security Bulletin, 73, 59.

[10] Osgood, D.W., Foster, E.M. and Courtney, M.E. (2010) Vulnerable Populations and the Transition to Adulthood. Future of Children, 20, 209-229. http://dx.doi.org/10.1353/foc.0.0047

[11] Auchincloss, A.H. and Hadden, W. (2002) The Health Effects of Rural-Urban Residence and Concentrated Poverty. Journal of Rural Health, 18, 319-336. http://dx.doi.org/10.1111/j.1748-0361.2002.tb00894.x

[12] Iezzoni, L.I., Killeen, M.B. and O’Day, B.L. (2006) Rural Residents with Disabilities Confront Substantial Barriers to Obtaining Primary Care. Health Research and Educational Trust, 41, 1259-1275. http://dx.doi.org/10.1111/j.1475-6773.2006.00534.x

[13] Kinnison, L.R., Fuson, S. and Cates, D. (2005) Rural Transition: What Are the Limitations?. Rural Special Education Quarterly, 24, 30-33.

[14] Barelds, A., Goor, I.V., Heck, G.V. and Schols, J. (2010) Quality of Care and Service Trajectories for People with Intellectual Disabilities: Defining the Aspects of Quality from the Client's Perspective. Scandinavian Journal of Caring Sciences, 24, 164-174. http://dx.doi.org/10.1111/j.1471-6712.2009.00701.x

[15] Beresford, B. (2004) On the Road to Nowhere? Young Disabled People and Transition. Child Care Health and Development, 30, 581-587. http://dx.doi.org/10.1111/j.1365-2214.2004.00469.x

[16] Kaehne, A. and Beyer, S. (2009) Transition Partnerships: The Views of Education Professionals and Staff in Support Services for Young People with Learning Disabilities. British Journal of Special Education, 36, 112-119. http://dx.doi.org/10.1111/j.1467-8578.2009.00427.x

[17] Dovey-Pearce, G., Price, C., Wood, H., Scott, T., Cookson, J. and Corbett, S. (2012) Young People (13 to 21) with Disabilities in Transition from Childhood to Adulthood: An Exploratory, Qualitative Study of Their Developmental Experiences and Health Care Needs. Educational and Child Psychology, 29, 86-100.

[18] Centers for Disease Control and Prevention (2014) 2013 NCHS Urban Rural Classification Scheme for Counties. http://www.cdc.gov/nchs/data/series/sr_02/sr02_166.pdf

[19] Health Resources and Services Administration. (2008) The National Survey of Children with Special Health Care Needs: Chartbook 2005-2006. http://mchb.hrsa.gov/cshcn05

[20] Georgia Department of Education. (2011) Georgia Transition Manual for Students with Disabilities: A Framework for the Local District. http://archives.gadoe.org/_documents/ci_exceptional/Transitional\%20Manual/0_TranMan_Title_and_Contents_9-11.p $\underline{\mathrm{df}}$

[21] Darrah, J., Evans, J.M. and Galambos, N.L. (2010) Community Services for Young Adults with Motor Disabilities-A Paradox. Disability and Rehabilitation, 32, 223-229. http://dx.doi.org/10.3109/09638280903071834

[22] Fowler, C.H., Test, D.W., Cook, J.C., Toms, O., Bartholomew, A. and Scroggins, L. (2014) Policy Implications of High School Reform on College and Career Readiness of Youth with Disabilities. Journal of Disability Policy Studies, 25, 19-29. http://dx.doi.org/10.1177/1044207313518072

[23] Mazzotti, V.L., Test, D.W. and Mustian, A.L. (2014) Secondary Transition Evidence-Based Practices and Predictors: Implications for Policymakers. Journal of Disability Policy Studies, 25, 5-18. http://dx.doi.org/10.1177/1044207312460888

[24] Wehman, P., Schall, C., Carr, S., Targett, P., West, M. and Cifu, G. (2014) Transition from School to Adulthood for Youth with Autism Spectrum Disorder: What We Know and What We Need to Know. Journal of Disability Policy Studies, 25, 30-40. http://dx.doi.org/10.1177/1044207313518071 